\title{
Avaliação das estruturas secretoras de Ocimum gratissimum var. macrophyllum Briq. (Lamiaceae) após extração dos constituintes voláteis
}

\author{
ALVAREZ, A.S. ${ }^{*}$; SANTOS, L.C. ${ }^{1}$; ZOGHBI, M.G.B. ${ }^{1 ;}$ SILVA, R.J.F. ${ }^{2}$ \\ ${ }^{1}$ Museu Paraense Emilio Goeldi (MPEG). Departamento de Botânica/Belém-PA. T. Perimetral 1903, CEP- \\ 660417-970, ${ }^{2}$ Museu Paraense Emilio Goeldi. Laboratório de Microscopia Eletrônica de Varredura/Coordenação \\ de Pesquisa e Pós-Graduação. Travessa Perimetral 1903, CEP-660417-970 Belém/ PA. *adalgisa_alvarez@ \\ yahoo.com.br
}

RESUMO: O impacto provocado nas estruturas secretoras de folhas adultas de Ocimum gratissimum var. macrophyllum após extração dos componentes voláteis utilizando-se diferentes métodos de extração foi investigado através de microscopia eletrônica de varredura (MEV). Secções transversais do ápice, da nervura central, e da margem mostraram superfície com cutícula estriada, estômatos diacíticos, tricomas tectores simples, filiformes, e glandulares peltados. Os peltados, com estrutura envolta por uma cutícula contendo o exsudado celular, variaram de 60 a $80 \mu \mathrm{m}$ de diâmetro sendo formados por uma porção apical multicelular com disposição radial formada por dois círculos concêntricos com 9 a 16 células. Na região central do ápice do tricoma peltado se identificou a presença de 4 células em forma de vértice dispostas sobre o pedúnculo, sendo esta a região mais externa formada por número variável de células. Os componentes voláteis das folhas adultas foram extraídos por hidrodestilação (HD), destilação-extração simultânea (DES), e solvente (SO). Os dados obtidos evidenciaram que o maior impacto nas estruturas secretoras ocorreu após extração por hidrodestilação quando comparado aos outros métodos utilizados. A porcentagem dos principais constituintes químicos, timol e $\gamma$-terpineno variaram de acordo com o método de extração: timol $(\mathrm{HD}=25,4 \%, \mathrm{SO}=$ $18,2 \%, \mathrm{DES}=54,8 \%)$ e $\gamma$-terpineno $(\mathrm{HD}=38,2 \%$, SO $=$ ausente, $\mathrm{DES}=13,7 \%)$.

Palavras-chave: Ocimum gratissimum var. macrophyllum, Lamiaceae, plantas medicinais, análise anatômica

\begin{abstract}
Evaluation of secretory structures of Ocimum gratissimum var. macrophyllum Briq. (Lamiaceae) after extraction of volatile compounds. The impact on the secretory structures of mature leaves of Ocimum gratissimum var. macrophyllum, after extraction of the volatile compounds using different extraction methods, was investigated by scanning electron microscopy (SEM). Cross-sections of the apex, the midrib and the margin showed surface with striated cuticle, diacitic stomata, single tector, filiform and glandular peltate trichomes. The peltate trichomes with a structure surrounded by cuticle containing the celllular exudate ranged from 60 to $80 \mu \mathrm{m}$ in diameter and consisted of a multicellular apical portion of radial arrangement formed by two concentric circles with 9 to 16 cells. In the central region of the peltate trichome apex, there were 4 cells in the form of a vertex arranged on the peduncle, and this was the most external region formed by a variable number of cells. The volatile compounds of the mature leaves were extracted by hydrodistillation (HD), simultaneous distillation-extraction (SDE) and solvent (SO). The obtained data evidenced that the major impact on the secretory structures occurred after extraction by hydrodistillation, compared to the other used methods.

The percentage of the major chemical constituents, thymol and $\gamma$-terpinene, changed according the extraction method: $(\mathrm{HD}=25.4 \%, \mathrm{SO}=18.2 \%$, SDE $=54.8 \%)$ and $\gamma$-terpinene $(\mathrm{HD}=38.2 \%$, SO $=$ absent, SDE $=13.7 \%)$.
\end{abstract}

Key words: Ocimum gratissimum var. macrophyllum, Lamiaceae, medicinal plants, anatomical analysis

Recebido para publicação em 20/08/2009

Aceito para publicação em 31/10/2012

Rev. Bras. PI. Med., Campinas, v.15, n.2, p.237-243, 2013. 


\section{INTRODUÇÃO}

Espécies da família Lamiaceae constituemse objeto de estudo científico sob o ponto de vista agronômico, químico, e anatômico, com o intuito de maximizar o rendimento de óleo essencial, comparar a variação dos constituintes químicos dos mesmos, e buscar novas fontes de substâncias importantes do ponto de vista econômico (Martins, 1998; Metcalfe \& Chalk, 1957; Figueiredo-Ribeiro, 1978; Fahn, 1979; Pino et al., 1998; Charles \& Simon, 1990; Werker et al., 1993; Tirillini et al., 1997).

A espécie Ocimum gratissimum conhecida na Amazônia por "alfavacão" é erva fortemente aromática, que apresenta alta variabilidade morfológica e química, existindo em duas variedades botânicas, var. macrophyllum e var. gratissimum. A variedade macrophyllum é cultivada no Pará em comercialização nas feiras e supermercados, e representa importante fonte de renda para os pequenos agricultores e feirantes, sendo comercializada como planta medicinal e para uso em banhos aromáticos. O óleo essencial da variedade macrophyllum é caracterizado pela alta porcentagem de $\gamma$-terpineno e timol (Zoghbi et al., 2007). Vários óleos essenciais dessa espécie apresentam atividade biológica, que estão associadas ao tipo químico dos mesmos: óleos ricos em timol (Pino et al., 1996; 1998; Vieira \& Simon 2000), eugenol (Demissew, 1993; Simon et al., 1999; Silva et al., 2004; Lemos et al., 2005), cinamato de etila (Dubey et al., 2000), eugenol/metileugenol (Vostrowsky et al., 1990), e geraniol (Charles et al. 1990; Vieira et al., 2001). Dentre estes, os óleos ricos em eugenol, possuem ação bactericida, principalmente frente à Staphylococcus aureus (Nakamura et al., 1997), e ação fungicida à Cryptococcus neoformans (Lemos et al., 2005); a atividade fungicida também foi citada para o tipo cinamato de etila (Dubey et al. 2000). O teor de óleos essenciais nos tecidos das plantas varia com o estágio de desenvolvimento das mesmas (Burbott \& Loomis, 1967), com as condições ambientais as quais se encontram submetidas, e, pode variar dependendo do método de extração utilizado (Charles \& Simon, 1990; Boutekedjiret et al., 2004; Benyoussef et al., 2004).

O objetivo deste trabalho foi realizar a análise qualitativa e quantitativa das estruturas secretoras das folhas de O. gratissimum var. macrophyllum L., após as mesmas serem submetidas à diferentes métodos de extração afim de comparar a eficiência desses métodos.

\section{MATERIAL E MÉTODO}

A espécie Ocimum gratissimum var. macrophyllum L. foi cultivada no campus de pesquisa do Museu Paraense Emílio Goeldi
(MPEG). Foram utilizadas folhas adultas medindo em média $14,5 \mathrm{~cm}$ de comprimento $\mathrm{x} 4,5 \mathrm{~cm}$ de largura, colhidas no estágio de floração da planta entre 8:30h e 9:00h, de um único espécime. Para cada experimento foram coletadas cinco folhas, e, imediatamente submetidas aos diferentes métodos de extração. $O$ início do experimento de extração dos voláteis por hidrodestilação (HD), destilaçãoextração simultânea (DES) e extração com solvente (SO) foi programado para que todas as amostras fossem fixadas em álcool á $70 \%$ no mesmo dia e horário aproximado. Folhas in natura também foram fixadas para comparação. O experimento foi realizado com 300 repetições. As folhas após serem submetidas aos três processos de extração foram fixadas em álcool $70 \%$, assim como as folhas in natura, e seccionadas em três regiões: ápice, nervura central e margem com aproximadamente $4 \mathrm{~cm}$ cada uma, com 20 amostras cada totalizando 60 amostras.

$\mathrm{Na}$ microscopia eletrônica de varredura foram utilizadas pequenas secções de todas as regiões da folha (apical, margem e, nervura central). As amostras foram fixadas em glutaraldeído por 24 horas, colocadas em solução de clorofórmio (3:1) para remoção da cera epicuticular com o objetivo de observar a superfície foliar. A desidratação foi realizada em série alcoólica progressiva $(80 \%$, $90 \%, 100 \%$ ), sob refrigeração por vinte minutos (Johansen, 1940). Após o ponto crítico, as amostras foram aderidas aos stubs com fita adesiva especial e recobertas por fina camada de ouro metálico de aproximadamente $9 \mathrm{~nm}$ de espessura sob alto vácuo.

A análise quantitativa foi realizada calculando-se a superfície foliar $\left(\mathrm{mm}^{2}\right)$ das secções do ápice, da nervura central e da margem basal, a partir de quatro quadrantes (Q1; Q2; Q3; Q4), com a contagem das glândulas secretoras colapsadas e não colapsadas, para verificar o impacto provocado pelos tratamentos com posterior cálculo dos valores médios.

\section{Extração dos componentes voláteis dos óleos}

Os óleos essenciais foram obtidos de folhas inteiras através de hidrodestilação (HD), em sistema de vidro do tipo Clevenger durante 3h. A bateria de destilação foi acoplada a um sistema de refrigeração para manutenção da água de condensação em mais ou menos $12^{\circ} \mathrm{C}$. Os óleos obtidos foram centrifugados durante $5 \mathrm{~min}$ a 3.000 r.p.m., desidratados com $\mathrm{Na}_{2} \mathrm{SO}_{4}$ anidro e novamente centrifugados nas mesmas condições e para análise cromatográfica utilizou-se solução contendo $2 \mathrm{ml}$ de óleo em $1 \mathrm{~mL}$ de hexano. 
Para destilação-extração simultânea (DES) as folhas inteiras $(1,46 \mathrm{~g})$ foram submetidas à extração em sistema de vidro do tipo Chrompack durante $3 \mathrm{~h}$, utilizando pentano como solvente $(5 \mathrm{~mL})$ e água deionizada $(50 \mathrm{~mL})$. Em seguida foram realizadas 50 repetições com 15 folhas $(7,46 \mathrm{~g}) \mathrm{com}$ o objetivo de fornecer a medida do volume de extrato pentânico obtido $(6 \mathrm{ml})$, com a solução pentânica analisada pela cromatografia gasosa.

$\mathrm{Na}$ extração por solvente (SO) o extrato hexânico foi obtido utilizando-se Soxhlet (SO1) durante $3 \mathrm{~h}$. Os rendimentos foram calculados em $\mathrm{g} \mathrm{mL}^{-1}$ com base na amostra livre de umidade. A umidade foi determinada utilizando-se luz na região do infravermelho em equipamento Mater mod. ID50.

\section{Análise da composição química}

Os óleos foram analisados através de cromatografia gasosa acoplada à espectrometria de massas (CG/EM), em sistema Hewlett Packard 5973, equipado com coluna capilar de sílica HP$5 \mathrm{MS}(30 \mathrm{~m} \times 0,25 \mathrm{~mm} \times 0,25 \mu \mathrm{m})$ nas seguintes condições operacionais: gás de arraste: hélio, em velocidade linear de $32 \mathrm{~cm}$ (medida a $100^{\circ} \mathrm{C}$ ); "split flow"; numa razão de 20:1; "septum sweep"; $10 \mathrm{~mL}$ min $^{-1}$; tipo de injeção: "splitless" (2 ul); temperatura do injetor de $220^{\circ} \mathrm{C}$; programa de temperatura: $60^{\circ} \mathrm{C}$ - $240^{\circ} \mathrm{C}\left(3^{\circ} \mathrm{C} \mathrm{min}\right)$; EM: impacto eletrônico, $70 \mathrm{eV}$; temperatura da fonte de íons e partes de conexão a $180^{\circ} \mathrm{C}$. Os componentes foram identificados através da comparação dos seus espectros de massas e índices de retenção (IR) com os de substâncias padrão, existentes nas bibliotecas do sistema e com dados da literatura (ADAMS, 2007). Os IR foram obtidos utilizando a série homóloga dos $n$-alcanos.

Foi realizada a quantificação em cromatógrafo gasoso equipado com detector de ionização de chama (CG-DIC) HP5890-II, e acoplado a um integrador HP 3396-II, coluna DB$5 \mathrm{MS}$, injeção "splitless", temperatura do injetor e do detector: $250^{\circ} \mathrm{C}$; programa de temperatura: $60^{\circ} \mathrm{C}$ $240^{\circ} \mathrm{C}\left(3^{\circ} \mathrm{C} \mathrm{min}\right)$; gás de arraste: hidrogênio

\section{RESULTADOS E DISCUSSÃO}

A análise anatômica qualitativa da superfície foliar de O. gratissimum var. macrophyllum revela superfície adaxial da folha com células de contorno sinuoso, evidente espessamento epicuticular e superfície abaxial com contorno mais definido por finas estriações da cutícula ornamentada (Figura $1 ; 2$ e 12).

Os estômatos são diacíticos de acordo com a descrição de Metcalfe \& Chalk (1957),

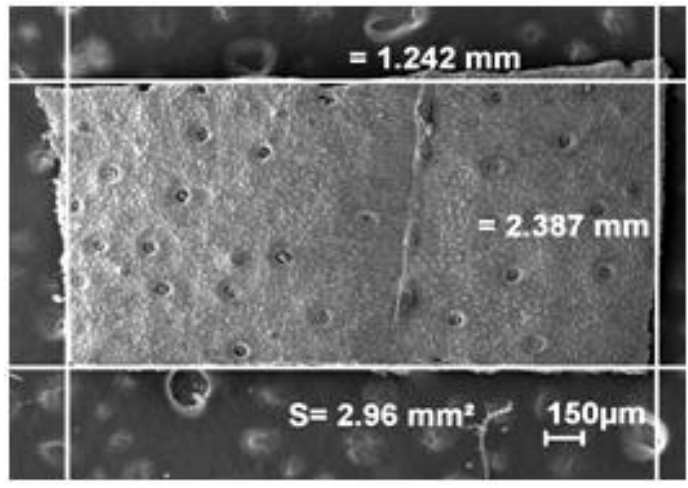

1

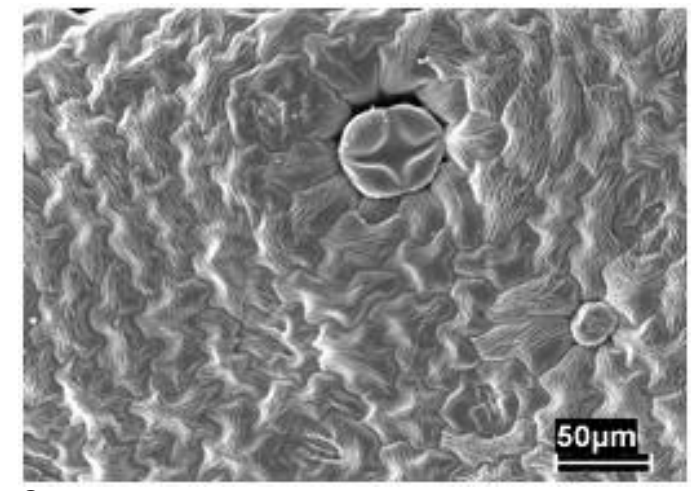

2

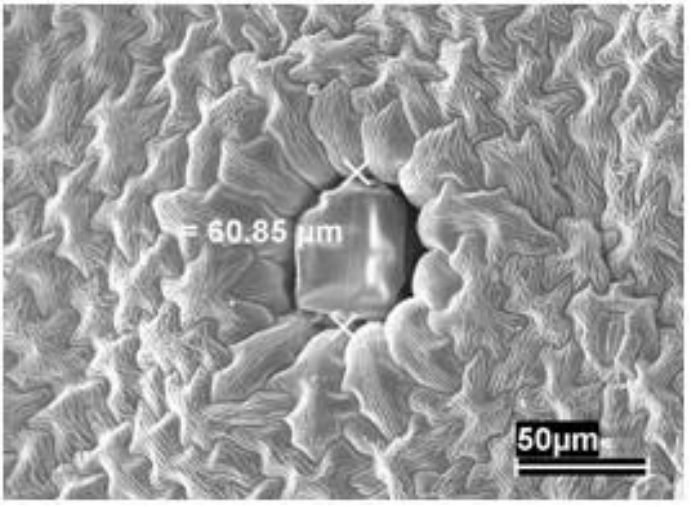

3

FIGURAS 1-3. Superfícies foliares após extração por hexano. 1- superfície adaxial em vista frontal, na região da nervura central. 2- sinuosidades, estriações epicuticulares, estômatos e tricomas glandulares peltados na superfície abaxial. 3- vista frontal de um tricoma glandular parcialmente colapsado. 

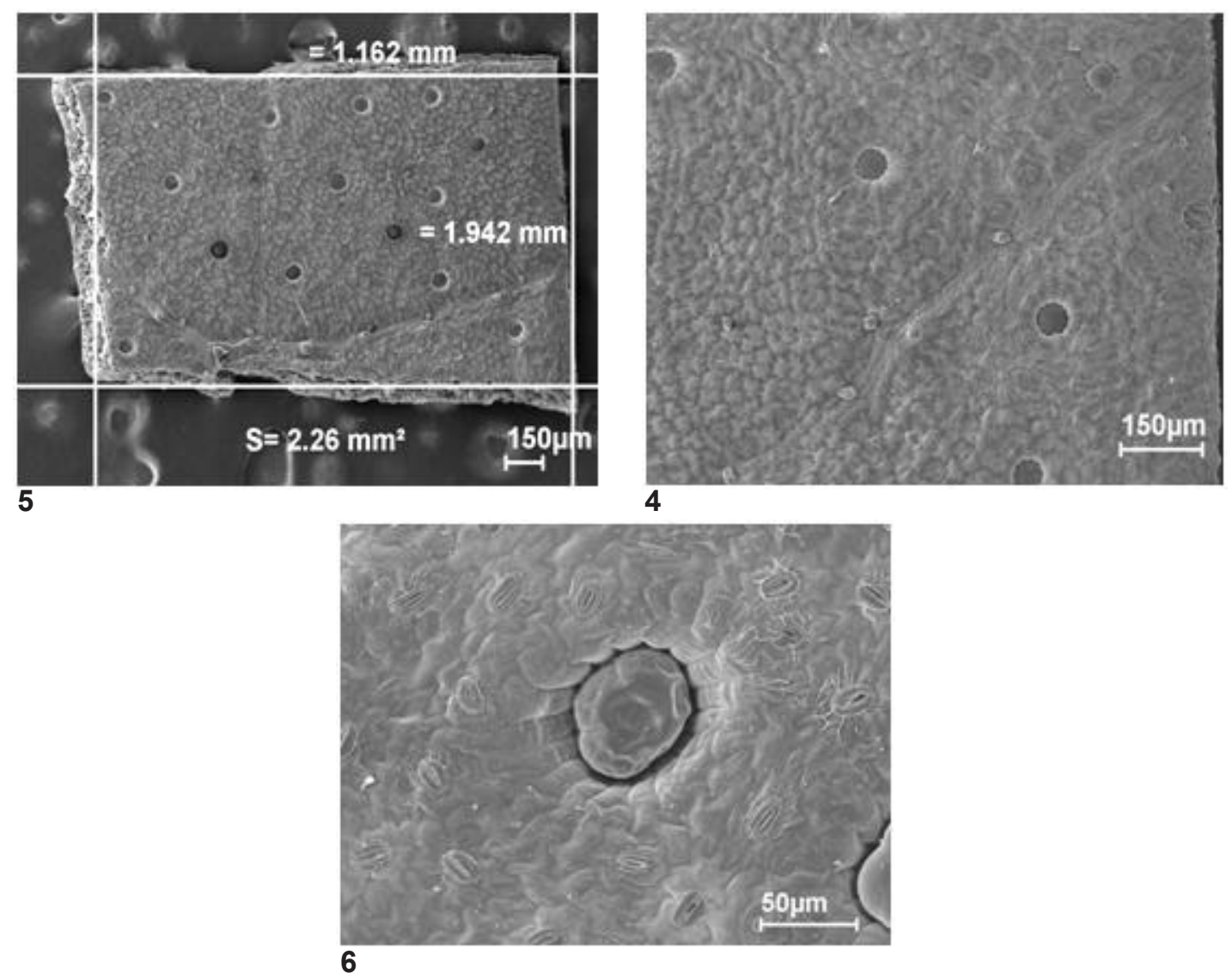

FIGURAS 4-6. Eletromicrografias da superfície abaxial após hidrodestilação; 4-Superfície abaxial em vista geral; 5- Tricomas glandulares peltados; 6-Detalhe do tricoma glandular peltado na superfície foliar abaxial.

comuns ao gênero, os apêndices epidérmicos representados por tricomas tectores simples, filiformes e glandulares (Figura 11). Os glandulares encontrados foram do tipo peltado (Figura 2, 3, 6, 11 e 12), considerados característicos para o gênero Ocimum L., descritos anteriormente por Martins (1998) para Ocimum selloi e, de modo semelhante por Ascensão et al. (1995) por ocasião da análise anatômica de Leonotis leonurus.. Esses tricomas glandulares apresentaram estrutura envolta por uma cutícula espessa contendo o exsudado celular, variando entre 60 a $80 \mu \mathrm{m}$ de diâmetro e formada por porção apical multicelular, com disposição radial formada por dois círculos concêntricos com 9 a 16 células. Na parte mais central do ápice da estrutura secretora, identificou-se a presença de 4 células em forma de vértice; no círculo mais externo, as células secretoras podem variar em número. Os tricomas peltados identificados em $O$. gratissimum var. macrophyllum haviam sido citados por Werker et al. (1993) e Werker (1995) para as estruturas secretoras de espécies do gênero Ocimum L., neste, a estrutura anatômica é similar a variedade selecionada, exceto pela variação no número de células secretoras. Na espécie $O$. basilicum, descrita por Werker (1993), a porção mais apical do tricoma peltado é formada por 4 células centrais únicas. Para Watanabe (1993), na espécie O. gratissimum, os tricomas peltados formam coroas circulares e cada uma possui de 4 à 12 células secretoras de óleo, o que sem dúvida corresponde aos resultados desse artigo.

Foram utilizadas cinco folhas provenientes da cada um dos métodos de extração, das quais foram seccionadas em 20 amostras para cada região (ápice, nervura central e margem) com um total de 60 amostras e 300 repetições. O número de estruturas colapsadas e não colapsadas foi estimado em todas as amostras. Foi observado que a extração por hidrodestilação obteve maior capacidade de colapsar as estruturas secretoras, que os demais métodos de extração. Esses dados, em comparação com os dados obtidos por Benyoussef et al. (2004), revelaram comportamento similar para a espécie Coriandrum sativum L., porém diferentes daos encontrados por Boutekedjiret et al. (2004) em Rosmarinus officinalis I.

A Tabela 1 revela a quantidade das estruturas secretoras presentes na superfície foliar e, na Tabela 2 foram expostos os componentes voláteis detectados nas amostras.

A extração por hidrodestilação mostrou-se 

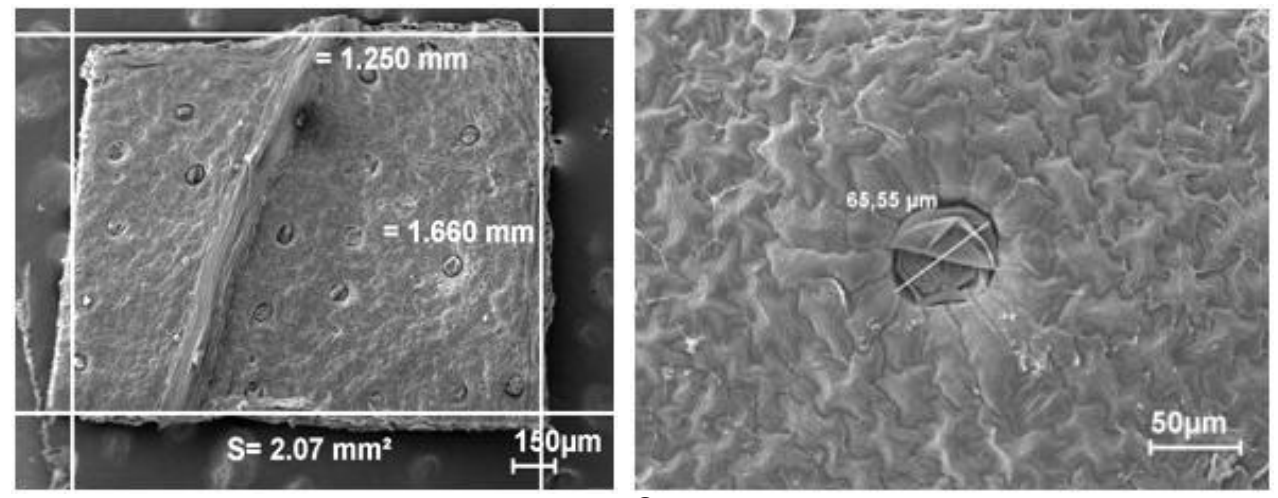

7

8

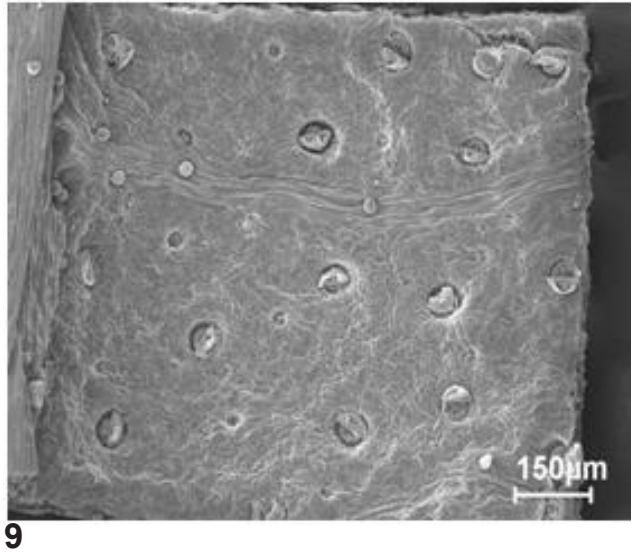

FIGURAS 7-9. Ocimum gratissimum var. macrophyllum. Eletromicrografias das folhas após extração da amostra in natura. 7-Superfície em vista geral; 8- Tricomas glandulares peltados em superfície estriada; 9-Detalhe do tricoma glandular com rompimento da cutícula.
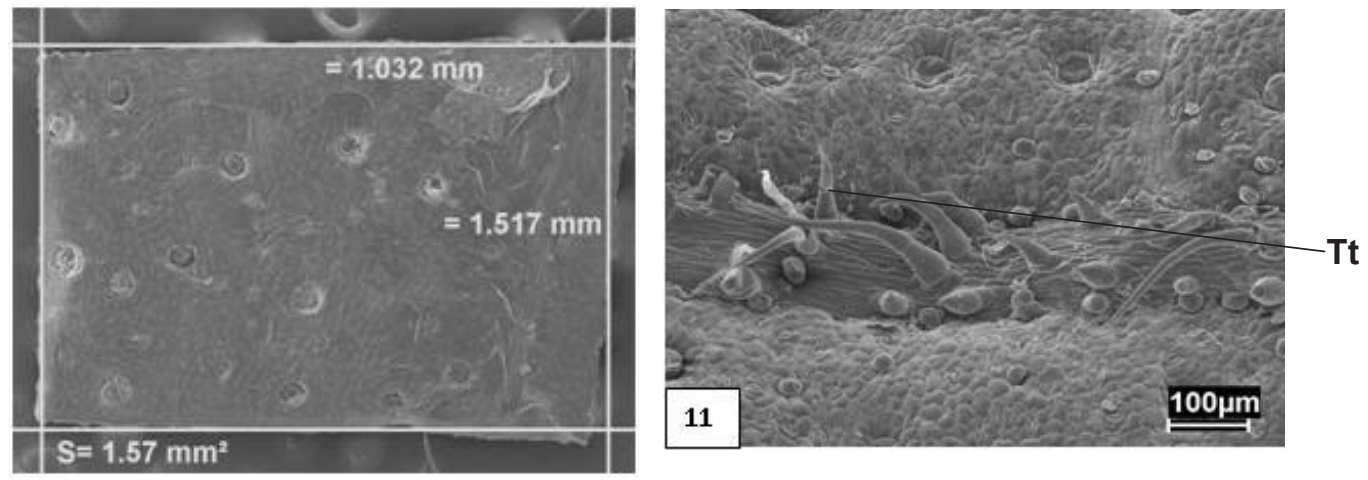

10

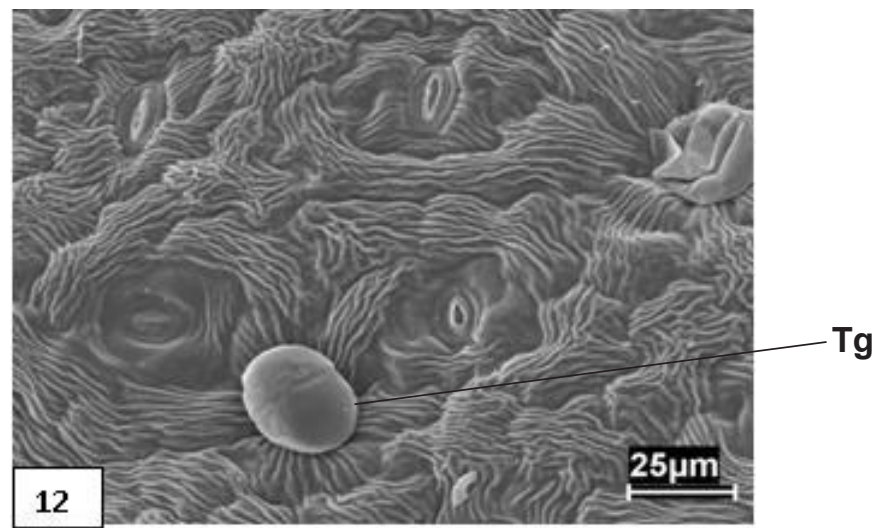

FIGURAS 10-12. Ocimum gratissimum var. macrophyllum. Eletromicrografias das folhas após destilação-extração simultânea. 10-Visão geral da superfície foliar adaxial; 11- Tricomas glandulares peltados e tectores na superfície estriada; 12-Tricoma glandular na superfície abaxial. Tt=tricoma tector;Tg=tricoma glandular. 
TABELA 1. Ação dos diferentes métodos de extração nas estruturas secretoras.

\begin{tabular}{llll}
\hline Hidrodestilação (HD) & Ápice & Nervura Central & Margem \\
\hline & Colapsadas: 9 & Colapsadas: 12 & Colapsadas: 19 \\
& Não colapsadas: 8 & Não colapsadas: 9 & Não colapsadas: 8 \\
\hline Destilação-extração & Colapsadas: 2 & Colapsadas: 5 & Colapsadas: 13 \\
simultânea (DES) & Não colapsadas: 23 & Não colapsadas: 8 & Não colapsadas: 9 \\
Solvente (SO) & Colapsadas: 9 & Colapsadas: 7 & Colapsadas: 10 \\
& Não colapsadas: 4 & Não colapsadas: 8 & Não colapsadas: 8 \\
\hline In natura & Colapsadas: 3 & Colapsadas: 6 & Colapsadas: 9 \\
& Não colapsadas: 20 & Não colapsadas: 8 & Não colapsadas 11 \\
\hline
\end{tabular}

TABELA 2. Componentes voláteis (\%) identificados nas folhas de Ocimum gratissimum var. macrophyllum.

\begin{tabular}{|c|c|c|c|}
\hline Componentes químicos & HD & so1 & DES \\
\hline$\alpha$-tujeno & 5,1 & 1,2 & 1,8 \\
\hline$\alpha$-pineno & 1,3 & 0,2 & 0,5 \\
\hline Canfeno & 0,1 & & \\
\hline Sabineno & 0,9 & 0,4 & 0,3 \\
\hline$\beta$-pineno & 0,4 & & 0,2 \\
\hline Mirceno & 4,5 & 2,2 & 1,6 \\
\hline m-menta-1(7),8-dieno & 0,6 & 0,2 & 0,2 \\
\hline$p$-menta-1(7),8-dieno & 0,2 & & \\
\hline$\alpha$-terpineno & 5,6 & 2,8 & 1,8 \\
\hline$p$-cimeno & 2,8 & 2,1 & 1,8 \\
\hline$\beta$-felandreno & 0,9 & 0,5 & 0,3 \\
\hline Limoneno & 0,4 & & 0,1 \\
\hline (E)- $\beta$-ocimeno & 0,3 & 0,2 & 0,1 \\
\hline$\gamma$-terpineno & 38,2 & 24,8 & 13,7 \\
\hline hidrato de cis-sabineno & 0,4 & 1,9 & 1,1 \\
\hline terpinoleno & 0,3 & & 0,1 \\
\hline$p$-cimeneno & 0,6 & 0,5 & 0,3 \\
\hline Linalol & 0,1 & 0,4 & 0,2 \\
\hline hidrato de trans-sabineno & 0,1 & & 0,3 \\
\hline$\delta$-terpineol & 0,3 & 0,3 & 0,3 \\
\hline terpinen-4-ol & 0,8 & 0,4 & 0,7 \\
\hline$\alpha$-terpineol & 0,1 & & 0,1 \\
\hline metiltimol & 0,9 & 0,8 & 0,7 \\
\hline Timol & 25,4 & 55,0 & 54,8 \\
\hline carvacrol & 0,4 & 1,1 & 0,9 \\
\hline eugenol & 0,1 & 0,4 & 0,2 \\
\hline$\alpha$-copaeno & 0,1 & & 0,2 \\
\hline$\beta$-cariofileno & 2,1 & 0,3 & 5,5 \\
\hline$\alpha$-humuleno & 0,8 & & 0,7 \\
\hline germacreno D & 1,1 & 1,3 & 2,1 \\
\hline$\beta$-selineno & 2,1 & 0,3 & 3,5 \\
\hline biciclogermacreno & 0,7 & & 1,1 \\
\hline$\delta$-cadineno & 0,3 & & 0,5 \\
\hline óxido de cariofileno & 0,2 & & 0,1 \\
\hline Total & 98,2 & 97.3 & 95.8 \\
\hline
\end{tabular}

HD = hidrodestilação, SO1 = extrato hexânico por Soxhlet, DES = destilação-extração simultânea. mais eficiente na extração dos voláteis, evidenciado pelo maior número de estruturas colapsadas $(C)$ em relação as não colapsadas (NC) nas três regiões estudadas (Figuras 1-3), por hidrodestilação (Figuras 4-6), na amostra in natura (Figuras 7-9) e na amostra extraída por destilação-extração simultânea (Figuras 10-12). Os rendimentos de óleo essencial e extratos obtidos foram de 1,2\% (HD), 0,3\% (DES) e $0,7 \%$ (SO1). A composição química do óleo essencial e do extrato pentânico foi comparável à citada na literatura para o quimiotipo da variedade macrophyllum (Zoghbi et al., 2007). Os principais componentes identificados foram timol (HD = $25,4 \%, \mathrm{DES}=55, \%)$ e g-terpineno $(\mathrm{HD}=38,2 \%$, $\mathrm{DES}=23,6 \%$ ). Quanto à elevada porcentagem de timol observada em todos os produtos obtidos durante a análise, pode nos levar a considerar este componente como critério qualitativo de análise.

\section{CONCLUSÃO}

A avaliação do impacto provocado nas estruturas secretoras de 0 . gratissimum var. macrophyllum após os procedimentos de extração revelam que o método de hidrodestilação, mostrou ser o mais eficiente para a extração em relação aos demais analisados, por apresentar maior quantidade de estruturas colapsadas indicando maior retirada de óleo das amostras da superfície das folhas em microscopia eletrônica de varredura.

\section{REFERÊNCIA}

ADAMS, R.P. Identification of Essential oil Components by Gas Chromatography/Mass Spectrometry. 4 ed. Carol Stream, Illinois: Allured Publishing Corporation, 2007. 804p.

ASCENSÃO, L.; MARQUES, N.; PAIS, M.S. Glandular trichomes on vegetative and reproductive organs of Leonotis leonurus (Lamiaceae). Annals of Botany, v.75, n.6, p.619-626,1995.

BENYOUSSEF, E.H. et al. Isolation of Coriander oils by different processes. Journal of Essential Oil Bearing

Rev. Bras. PI. Med., Campinas, v.15, n.2, p.237-243, 2013. 
Plants, v.7, n.2, p.129-135, 2004

BOUTEKEDJIRET, C. et al. Isolation of rosemary oils by different processes. Journal of Essential Oil Research, v.16, n.3, p 195 199, 2004

CHARLES, D.J.; SIMON, J.E. Comparison of extraction methods for the rapid determination of essential oil content and composition of basil (Ocimum spp.). Journal of the American Society for Horticultural Science, v.115, n.3, p.458-462, 1990.

CHARLES, D.J.; SIMON, J.E.; WOOD, K.V. Essential oil constituents of Ocimum micranthum Willd. Journal of Agricultural and Food Chemistry, v.38, n.1, p.120122, 1990.

DEMISSEW, S. A description of some essential oil bearing plants in Ethiopia and their indigenous uses. Journal of Essential Oil Research, v. 5, n. p. 465-479, 1993.

DUBEY, N. K. et al. Antifungal properties of Ocimum gratissimum essential oil (ethyl cinnamate chemotype). Fitoterapia, v.71, n.5, p. 567-569, 2000.

FAHN, A. Secretory tissues in plants. 1 ed. London: Academic Press, 1979. 302p.

FIGUEIREDO-RIBEIRO, R.C.L. et al. Morphology and essential oil in the taxonomy of Ocimum nudicaule Benth. (Labiatae). Anais da Academia Brasileira de Ciências, v.32, n.(supl.), p. 65-71, 1978

JOHANSEN, D. A. Plant microtechnique. New York: MacGraw-Hill Book Company., 1940. 523p.

LEMOS, J. A. et al. Antifungal activity from Ocimum gratissimum L. towards Cryptococcus neofromans. Memórias do Instituto Oswaldo Cruz, v.100, n.1, p. 55-58, 2005

MARTINS, E.R. Estudos em Ocimum selloi Benth.: isoenzimas, morfologia e óleo essencial. In: MING, L.C. et al. (Eds.). Plantas medicinais, aromáticas e condimentares: avanços na pesquisa agronômica. Botucatu: UNESP, 1998. p.97-126.

METCALFE C. R.; CHALK, L. Anatomy of the dicotyledons. 2 ed. Oxford: Claredon Press, 1957. 1500p.

NAKAMURA, C.V. et al. Antibacterial activity of Ocimum gratissimum L. essential oil. Memórias do Instituto Oswaldo Cruz, v.94, n.5, p. 675-678,1997.

PINO, J.A; ROSADO, A.; FUENTES, V. Composition of the essential oil from the leaves and flowers of Ocimum gratissimum L. grown in Cuba . Journal of Essential Oil Research, v.8, n.2, p. 139-141, 1996.

PINO, J.A.; GARCIA, J.; MARTINEZ, M.A. A comparison between the oil, solvent extract and supercritical carbon dioxide extract of Ocimum gratissimum L. Journal of Essential Oil Research, v.10, n.1, p. 575-577, 1998.

SILVA, M.G.V. et al. Composition of essential oils from three Ocimum species obtained by steam and microwave distillation and supercritical $\mathrm{CO}_{2}$ extraction. Arkivoc, part 6, p.66-71, 2004. Disponível em: http:// www.arkat-usa.org/ark/journal/2004/I06_Gottlieb/OG1005G/OG-1005G.asp. Acesso em: 20 dez. 2008

SIMON, J.E. et al. Brasil: a source of aroma compounds and a popular culinary and ornamental herb. In: Janick, J. (Ed.). Perspectives on new crops and new uses. , Alexandria: ASHS Press, 1999. p. 499-505

TIRILLINI, B.B.; MENGHINI, A.A.; PELLEGRINO, R.R. Constituents of the leaf secretory hairs of Agastache foeniculum Kuntze. Journal of Essential Oil Research, v.9, n.1, p.19-21, 1997.

VIEIRA, R. F.; SIMON, J. E. Chemical characterization of basil (Ocimum SPP.) found in the markets and used in traditional medicine in Brazil. Economic Botany, v.54, n.2, p. 207-216, 2000.

VIEIRA, R.F. et al. Genetic diversity of Ocimum gratissimum L. based on volatile oil constituents, flavonoids and RAPD markers. Biochemical Systematics and Ecology, v.29, n.3, p. 287-304, 2001.

VOSTROWSKY, O. et al. Essential Oil of Alfavaca, Ocimum gratissimum, from Brazilian Amazon. Zeitschrift für Naturforschung, v.45, n. (Complement), p. 1073-1076, 1990.

WATANABE, S. Morphological observations on the gland hairs or oil gland of leaf surface in some aromatic plants. Journal of the Yamagata Agriculture and Forestry Society, v.0, 50, p.73-76, 1993.

WERKER, E. et al. Glandular hairs and essential oil in developing leaves of the Ocimum basilicum $\mathrm{L}$. (Lamiaceae). Annals of Botany, v.71, n.1, p. 43-50, 1993.

WERKER, E. Function of essential oil-secreting glandular hairs in aromatic plants of Lamiaceae: a review. Flavour and Fragrance Journal, v.8, n.5, p. 249-255, 1993.

WERKER, E.; RAVID, V.; PUTIEVSKY, E. Structure of glandular hair and identification of the main components their secreted material in some species of the Labiatae. Israel Journal of Botany, v.34, n.1, p.31 - 45, 1985.

ZOGHBI, M.G.B. et al. Variation in volatiles of Ocimum campechianum Mill. and Ocimum gratissimum L. cultivated in the North of Brazil. Journal Of Essential Oil Bearing Plants, v.10, n.3, p. 229-240, 2007. 